HELGE TOUTENBURG

Vorhersage in linearen Modellen 



\section{Vorhersage in linearen Modellen}

Dr. rer. nat. HELGE TOUTENBURG

Zentralinstitut für Mathematik und Mechanik der Akademie der Wissenschaften der DDR

Mit 3 Tabellen

AKADEMIE - VERLAG - BERLIN 1975 
Erschienen im Akademie-Verlag, 108 Berlin, Leipziger Str. 3-4

(c) Akademie-Verlag, Berlin, 1975

Lizenznummer: $202 \cdot 100 / 405 / 75$

Gesamtherstellung: VEB Druckerei „Thomas Müntzer“, 582 Bad Langensalza

Bestellnummer: 7618844 (6143) · LSV 1075

Printed in GDR

EVP 28, - 